Jenny Lederer*

\title{
Lexico-grammatical alignment in metaphor construal
}

https://doi.org/10.1515/cog-2017-0135

Received November 10, 2017; revised August 23, 2018; accepted August 24, 2018

Abstract: This study concerns the distribution of metaphorical lexis in discrete syntactic constructions. Source and target seed language from established conceptual metaphors in economic discourse is used to catalogue the specific patterns of how metaphorical pairs align in five syntactic constructions: A-NP, N-N, NP-of-NP, V-NP, and X is Y. Utilizing the Corpus of Contemporary American English (Davies, Mark. 2008-present. The corpus of contemporary American English: 450 million words, 1990-present [Online Corpus]), the examination includes 12 frequent metaphorical target triggers combined with 84 source triggers to produce 2,016 ordered collocations, i.e. investment freeze and turbulent market. Through detailed type and token counts, results confirm that source domains function as conceptual material used to structure the target domain and disproportionally fill syntactic positions associated with predication (cf. Sullivan, Karen. 2009. Grammatical constructions in metaphoric language. In B. LewandowskaTomaszczyk \& K. Dziwirek (eds.), Studies in cognitive corpus linguistics. Frankfurt: Peter Lang Publishers; Sullivan, Karen. 2013. Frames and constructions in metaphoric language. Amsterdam: John Benjamins Publishing). Given a lexeme's origin - source or target - when used in source-target metaphors, syntactic alignment can be predicted, market climate is metaphorical, climate market is not. Exceptions to these strong tendencies are explained through genre-specific lexicalization processes in which predicate denoting terms like bubble (market bubble) establish themselves as domain modifiers (bubble market) in economic jargon. Through quantitative techniques to gage metaphorical conventionality and lexical versatility, corpus methodology is used to define and inform the value of frequency effects in cataloguing and understanding metaphorical lexicalization.

Keywords: metaphor, corpus linguistics, syntax, economic discourse

*Corresponding author: Jenny Lederer, Department of English Language and Literature, San Francisco State University, San Francisco, CA, USA, E-mail: lederer@sfsu.edu 


\section{Introduction}

This article focuses on the lexicalization of metaphors at the level of topic-specific English discourse. The terms 'lexicalization' and 'lexicalization pattern' here refer to regularities in how conceptual components are encoded in a lexical item or phrase. While touching on several aspect of metaphor distribution, the primary focus of inquiry concerns the alignment of metaphorical domains in specific syntactic positions. It has been observed that semantic dependency relations correspond to and predict metaphorical lexicalization processes (Sullivan 2007, 2013). For example, absent quite rich context, certain combinations of economic lexis in noun-noun compounds will be understood as metaphorical while the reverse ordering will not:

$\begin{array}{ll}\text { Metaphorical } & \text { Literal } \\ \text { investment climate } & \text { climate investment } \\ \text { debt storm } & \text { storm debt } \\ \text { market drought } & \text { drought market } \\ \text { bank health } & \text { health bank }\end{array}$

The asymmetrical pattern of what Dunn (2015: 5) terms 'source-target metaphors' - metaphorical phrases with contextually stable interpretations - sheds light on the unidirectional, systematic nature of metaphorical mappings, as explained by the hypothesis that metaphorical mappings from source to target are unidirectional (Lakoff and Johnson 1980; Kövecses 2010). This problem is very important for cognitive linguistics: Even though metaphoric utterances remain the primary means of observing metaphor, the analysis of metaphoric utterances on a linguistic or grammatical level has drawn only limited attention. The asymmetries in source and target syntactic distribution, however, lend themselves to falsifiable claims. The main contribution of this paper is, thus, to introduce a large-scale, quantitative analysis of source-target trigger alignment in order to test the claim that source-domain material, when combined with target lexis, will asymmetrically fill syntactic positions that serve predicating functions. In other words, to a large extent, the metaphorical load of a source-target metaphor is syntactically predictable.

Although the instantiation of conceptual metaphors in natural languages is unpredictable at the level of the individual lexeme, the overall lexicalization of source-target phrases is not haphazard. Beginning in Croft (1993), Jäkel (1993), Kövecses (2002) and more thoroughly in Sullivan (2007), metaphor researchers have observed ordering asymmetries in the syntactic alignment of metaphorical lexis (see also Dancygier and Sweetser 2014; Sullivan 2013, 2016). Patterns in 
metaphorical language can be identified, to some extent, by probing native speakers about their own language use. But this technique often fails because speakers have inconsistent explanations of what they can and do say. Although corpus linguists have for some time used frequency statistics to investigate the relationship between conceptual metaphor and the set phraseology of topical discourse (Charteris-Black 2004; Deignan 2005, 2012; Demmen et al. 2015; Koller et al. 2008; Lederer 2016; Stefanowitsch 2005, 2006), this study is the first to empirically examine syntactic asymmetries by systematically cataloguing a significant collection of corpus data, responding to a call to fill a gap in the literature (Sullivan 2016: 147). While the exploration focuses on economic metaphors as a case study (cf. Boers and Demecheleer 1997; Shenker-Osorio 2012), the methods and findings should extend to a variety of other well researched target domains including the environment (Skinnemoen 2009; Volmert et al. 2013), immigration (Baker et al. 2008; Charteris-Black 2006; Cisneros 2008; El Refaie 2001; O’Brien 2003; Santa Ana 1999, 2002), and emotion (Kövecses 2010; Oster 2010), among others.

\subsection{Theory}

The overall approach is built on one strand of Conceptual Metaphor Theory, which assumes the metaphors that occur in natural language are based on systematic bindings between set source and target domains. These links arise, at an unconscious level, from real world co-occurrences between realms of experience and the abstract concepts associated with them (Gallese and Lakoff 2005; Lakoff and Johnson 1980, Ch. 12; Lakoff 1993). For example, the conflation of physical, translational motion and the 'passage' of time results in a set of metaphors used to understand the abstract notion of time (Núñez and Sweetser 2006; Moore 2006, 2014), demonstrated in examples like Christmas is around the corner. In another illustration, the concurrence of quantity increase with vertical growth (as when water is poured into a glass) gives rise to the primary conceptual metaphor QUANTITY IS VERTICALITY (Lakoff and Johnson 1980; Grady 1997, 1999) and is manifested in language in examples like rent prices have risen again. Primary metaphors like STATES ARE LOCATIONS and CHANGE IS MOTION combine with others to structure more complex metaphors and build detailed role and inference information. For instance, in the common mapping, LIFE IS A JOURNEY, consistent experience with travel structures common elements associated with the journey frame: traveler, vehicle, origin, destination, and path (Fillmore 1982, 1985; Fillmore and Baker 2010). These frame elements systematically map over to construct the concept of life and life stages: birth as origin, death as destination, choices as paths, impediments as obstacles. The notion that metaphor is primarily conceptual is not 
uncontroversial (Gibbs 2017), and although the conceptual nature of metaphorical mappings has been supported experimentally in the psychological literature (cf. Boroditsky 2000; Casasanto and Boroditsky 2008; Gibbs 2017, Ch. 5; Thibodeau and Boroditsky 2011, 2013, among others), many in the linguistic community dispute metaphor as a structural and grammatical primitive (Pinker 2006, 2007) or take a hedged view contending that some metaphors are conceptual and unconscious, while others conscious and deliberate (Steen 2007, 2011, 2015).

Conceptual metaphor adversaries, led by vocal critics like Steven Pinker (2007), argue against the cognitive nature of metaphor mapping. "People don't dig down to a conceptual metaphor every time they understand a conventional one" and "Though metaphors are omnipresent in language, many of them are effectively dead in the minds' of today's speakers and the living ones could never be learned, understood, or used as reasoning tools unless they were built out of abstract concepts that capture the similarities and differences between the symbol and symbolized" (p. 248, 276 respectively). Through the lens of lexicalization, old debates about conscious metaphor activation can be abandoned and replaced with systematic measures of how lexical items come together to produce metaphorical phraseology, whether conventional (i.e. frequent in the speech community) or creative and novel (infrequent expressions that fit in line with established conceptual metaphors). Taking the view that conceptual metaphors serve as cognitive input used in lexicalization processes (cf. Talmy 2000a, 2000b), this study introduces new methodology in the investigation of lexicalization. By preselecting established metaphors and then searching for lexical patterns, the methodology inverts the common approach to metaphor study, in which existing language is used to find conceptual mappings. This methodological inversion allows for a systematic examination of several important research questions pertaining to the interface between metaphor, grammar, and the lexicon.

\subsection{Structure}

The paper is structured as follows. After providing theoretical background (\$2) and outlining the methodology (§3), the first study (§4) examines the syntactic realization of source and target pairings. Acknowledging metaphorical mappings are more constrained by autonomous target domains, Sullivan (2013) hypothesizes a preference for target-domain language to populate semantically more autonomous syntactic positions in modifier-noun constructions, predicting that source and target triggers should align with predicate-specifying and argument-specifying syntactic positions, in that order. Given a lexeme's origin - source or target - we should be able to predict syntactic alignment. To test this hypothesis, seed words like financial 
and storm (identified as frequent metaphor triggers in The Economist magazine [Lederer 2016]) are used to probe fixed and semi-fixed economic phraseology. Using the Corpus of Contemporary American English (Davies, 2008-present), the largescale examination includes 12 frequent metaphorical target triggers (bank, invest, market, firm, debt, finance, rate, price, capital, growth, economy, money) combined with 84 source triggers (including lemmas like sail, storm, channel, conditions, freeze, cloudy, turbulent, ailing, and health) to produce 2016 ordered pairings, i.e. investment freeze and turbulent market. Each lexical combination is evaluated for its rate of occurrence in five syntactic constructions: NP-of-NP (captain of finance; wave of capital), A-NP (economic headwinds; ailing economy), N-N compound (debt bubble; bubble market) V-NP (steer the economy), and X is Y (the economy is a sinking ship).

The notion that metaphorical mappings feed lexicalization patterns is by no means an endorsement for a 'slot and filler' (Sinclair 1991: 109) approach to language representation. Instead, through a series of measurements, the second series of studies probe the 'single choice' or 'idiom principle' (Sinclair 1996, 1998, 2004). Under this 'co-selection' view (Sinclair 1996, 1998, 2004), words or words and grammatical constructions are often chosen simultaneously to express a particular meaning (Herbst et al. 2011: 27). The co-selection of source and target triggers is explored through three measures of lexicalization (§5). In the first measure, metaphorical phrases are catalogued along a scale of conventionality and entrenchment (Gibbs 1984) (\$5.1). Frequency statistics are used as a proxy for conventionalization (Cheng 2012). On one end, highly frequent collocations of set source and target triggers occur as common fixed or semi-fixed phrases; on the other end, more creative and novel pairings will be less frequent in corpus data, and, thus, not considered conventionalized, metaphorical jargon. Economic phraseology can be further dissected by looking at patterns of source and target trigger behavior. A second line of investigation (\$5.2), focuses on distributional coverage and 'metaphorical combinability' (Hausmann 2007): Which source triggers are the most permissive in their ability to co-occur with target triggers and vice-versa? The factors that might contribute to combinability scores include a lemma's rate of lexical variation, base rate frequency in economic discourse, and keyness score - relative frequency in economic discourse compared to overall use in English (Cheng 2012; Ahmad 2005).

In a final section of analysis (§5.3), the study turns to asymmetric ordering patterns of specific source and target pairings to examine features that might contribute to token frequency differences between sequences of the same triggers when both sequences can be used metaphorically. For example, in COCA, financial health occurs much more regularly than healthy finances. Both possibilities come from the same metaphor, THE ECONOMY IS AN AILING BODY; however, the source and target triggers do not fill the A-N slots at the same rate. Based on the examination of 
base-rate scores and keyness statistics, these asymmetries seem to be motivated by discourse context (public discussion of economic topics focuses more on macroversus micro-economics) rather than overall word frequency differentials.

\section{Background}

Since the inception of Conceptual Metaphor Theory, specific mappings between source and target domain have been considered to be systematic and part of a hierarchical ontology of metaphors (Grady 2005; Kövecses 2010, 2015; Lakoff and Johnson 1980). Recently, a top-down, knowledge system approach, from superordinate to basic to subordinate instantiations of metaphor families has been carried out by a variety of research groups (Dodge et al. 2015; David et al. 2016; see Shutova 2015 for an overview). Modeled after the FrameNet ontology (Fillmore and Baker 2010), metaphorical source domains range from general to specific, and at each level of subordination, can inherit roles and features from a parent (Dodge et al. 2015). Metaphors that participate in structuring economic discourse demonstrate the hierarchical nature of source and target mappings. At a superordinate level, the economy is structured like other systemic target domains. Systems of all kinds, such as social organizations, governments, corporations, climate, and physical organisms are understood primarily through the same sets of metaphors. These metaphors all have one commonality: the source domains represent different instantiations and elaborations of physical structures vis-à-vis the primary metaphor ABSTRACT SYSTEMS ARE PHYSICAL STRUCTURES (Kövecses 2010). The physical structures that serve as subcases of this superordinate metaphor, however, vary: ABSTRACT COMPLEX SYSTEMS can be understood through several structure types including MACHINES, BUILDINGS, PLANTS, and HUMAN BODIES (Kövecses 2010: 156) as illustrated in Table 1.

Table 1: The hierarchical nature of conceptual metaphors illustrated through metaphors for the economy.

Superordinate level: COMPLEX SYSTEMS ARE PHYSICAL STRUCTURES

\begin{tabular}{|c|c|}
\hline $\begin{array}{l}\text { Subordinate level: ECONOMY IS AN (AILING) } \\
\text { HUMAN BODY }\end{array}$ & $\begin{array}{l}\text { ECONOMY IS A MOVING } \\
\text { VEHICLE }\end{array}$ \\
\hline Mappings & Mapping \\
\hline $\begin{array}{l}\text { blood circulation } \rightarrow \text { money transfer } \\
\text { disease } \rightarrow \text { economic performance }\end{array}$ & $\begin{array}{l}\text { forward motion } \rightarrow \text { economic performance } \\
\text { rate of motion } \rightarrow \text { economic growth }\end{array}$ \\
\hline Examples: money circulation, ailing economy & $\begin{array}{l}\text { Example: sinking economy, economic } \\
\text { acceleration }\end{array}$ \\
\hline
\end{tabular}


In some cases, a basic source domain, such as a vehicle, is evoked through a very precise image as in (1):

(1) The 2008 downturn was the Titanic of all financial crashes.

Here, the source domain is elaborated through an idiomatic, salient exemplar, the Titanic, with unique reasoning - devastation, many people affected, historical, etc. and these inferences are transferred over to our understanding of the target domain - the 2008 downturn was grave in scale and consequence (referred to as entailment or inference transfer in Conceptual Metaphor Theory [Lakoff and Johnson 1980]). The simultaneous activation of connected source domains TITANIC<SHIP < VEHICLE is what explains the systemic nature of conceptual metaphors. Metaphors are not learned as lists of unrelated mappings (Grady 1997; Lakoff and Johnson 1999); like other aspects of grammar, metaphorical reasoning is abstracted from specific to general (Feldman and Narayanan 2004; Lakoff 2008). This hidden complexity is crucial in explaining how intricate abstract concepts like the economy are metaphorically structured and lexically instantiated. Economic discourse and reasoning is arranged through multiple metaphors functioning at varying levels of specificity (McCloskey 1986; Boers 1997; Boers and Demecheleer 1997; Skorczynska and Deignan 2006; Kövecses 2010; Shenker-Osorio 2012; Lederer 2016).

\subsection{The economy as a metaphorically based cognitive model}

Individual source-target mappings work in tandem to organize the cognitive models that structure complex abstract concepts (Lakoff 1987). The economy, as a metaphorical model, fits several types outlined by Steen (Steen 2011: 57): it is "implicit" in nature - reflective of cultural models; "official”, in the sense that it is instilled through education and the academy, while at the same time 'emergent' - economic discourse arises through social interaction, such as within the business and academic economic communities.

Economic concepts are inextricably linked to a metaphorical understanding of money. The target domain, MONEY (currency), is structured through an understanding of the movement of liquid or water. Money circulation is the flow of capital from banks to consumers to business and back again as illustrated in examples taken from The Economist magazine (2)-(5): 
(2) Footloose capital generates bubbles as it rushes in...

(3) ...as the fall in exports was exacerbated by a sudden drying up in trade finance.

(4) Best to be liquid in case the well runs dry.

(5) Prices would have gone down even further had not transactions dried to a trickle.

The source domain LIQUID is instantiated and extended through rich concepts related to water including bubbles (soapy water) and wells (containers for water) along with properties important in the description of water like hot and cold (ACTIVITY IS HEAT; INACTIVITY IS COLD) and numerous manners of movement like rush or trickle.

Because liquid serves as the source domain for the understanding of money, a metaphorical understanding of the economy also relies on several source domains that have to do primarily with water. These are WEATHER EVENTS, i.e. rain, storms, clouds, BODIES OF WATER like seas, oceans, channels, rivers, and the VEHICLES that navigate waterways: boats and ships. The concept of climate is used to discuss public sentiment on economic issues and economic performance is understood through perceptions pertaining to weather conditions: bad weather means negative performance; good weather is positive as in (6)-(9):

(6) ...meaning the banks have buffers to weather a medium-sized storm.

(7) Edwards has dubbed these conditions an "ice age" which he predicts will extend ...

(8) if drought is responsible for some of China's price pressure, a deluge of credit is to blame for the rest. So China-watchers were quick to welcome a turn in the monetary weather this week.

(9) The euro crisis casts a chill over a sunnier economic picture ...

Weather language comes in a wide variety of lexis including specific conditions like stormy, sunny, wind, and drought, and concepts related to weather patterns like season, climate, and forecast.

The economy is assumed, like a vehicle, to move forward at varying rates of speed, mapping to slow and fast progress. Because water-based metaphors 
structure monetary theory, the vehicle is most commonly a ship or boat. Policymakers direct the economy, just like captains steer ships. A poorly performing economy is likened to a sinking ship and economic or financial failure is discussed as if it were a shipwreck as in (10)-(14):

(10) What is worrying is that today's traders are in truly uncharted (and very cold) waters...

(11) Partly they may have been buoyed by robust business conditions in China.

(12) ABC's 320m customers... are reason enough to go ahead regardless of turbulent conditions.

(13) Conditions are undeniably frothy.

(14) Over time the economy will be weighed down by all these costs, like a barnacle-encrusted ship.

In a different metaphor with an unrelated source domain, the economy is understood through the frame of a (usually sick) human body, a type of extended personification (Shenker-Osorio 2012: 43) as illustrated in (15)-(17):

(15) It is unreasonable to ask policymakers to worry about the long-term side effects of their medicine.

(16) ...while banks are still in surgery, but today's cure may well be the source of tomorrow's ills.

(17) When an economy sneezes, its trading partners catch a cold, as demand for their exports falls.

The germs can also spread through financial channels ...

In the analysis of a complex target like the economy, it is not surprising to find a concept, like temperature, playing a role in more than one source domain. For example, body temperature is one measurement used to diagnose health and disease in a medical setting, but air temperature is also a concept integral to our understanding of weather and machines. Thus, lexemes like hot and cold can activate alternative source domains in various contexts and can be compatible with multiple source domains simultaneously. The activation of temperature differentially applies to multiple metaphors. High temperature in a body is potentially 
grave, a sign of illness in the metaphor ECONOMY IS AN (AILING) HUMAN BODY as illustrated in (18):

(18) Banks are asked to raise a sum of money; the lead managers take the market's temperature and advise about the yield and maturity investors want.

But when used in reference to the ECONOMY IS A WEATHER EVENT, heat, up to a certain point, is good and cold is bad (as prescribed by the underlying metaphor HEAT IS ACTIVITY). These inferences are shown in (19) and (20):

(19) If this is right, rich-world economies may enjoy a boost after the end of the winter freeze.

(20) BEIJING recently suffered its lowest temperature in 59 years, but the economy is sweltering.

As the above examples demonstrate, figurative language often draws on more than one source domain. The intersecting nature of these related source domains helps explain the prevalence of lexis compatible with more than one metaphor. Metaphorical lexis activate source domains that that overlap in their conceptual structure as illustrated in Figure 1:

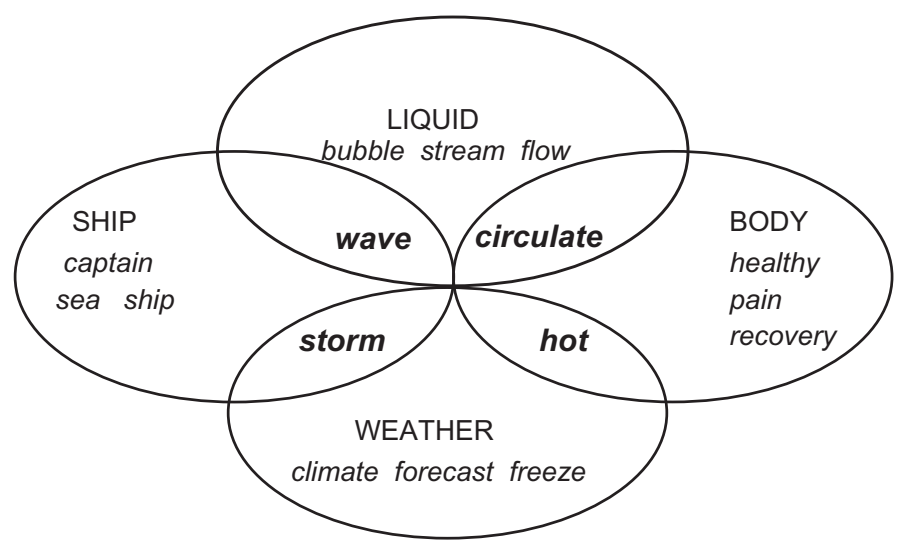

Figure 1: Overlapping source domains give rise to metaphorical lexis that build the cognitive model.

The aforementioned conceptual metaphors work together to build a complex cognitive model of the economy as a ship moving through potentially treacherous waters due to inclement weather. Ruiz de Mendoza (2017: 147) discusses this type 
of overlap as epiphenomenal, a case of a frame complex enriching an image schema complex. In the vehicle model, the image schema involves forward motion along a path; the vehicle frame and obstacle frame elements are accordingly filled by conceptually coherent scenarios, ship and treacherous waters respectively. In a separate model, individual economies are understood as sick hospital patients, in need of medical attention, threatening to contaminate other economies. It should be noted, however, that the lexical overlap with terms like hot and circulate, is due to shared, but independent, concepts like temperature and liquid motion across unrelated source domains: the human body can run a fever (negative); whereas a vehicle engine needs heat for energy (positive).

\subsection{Background - lexicalization of source domains}

The use of corpus methodology to examine the lexicalization patterns of conceptual metaphors has been approached from several angles (Charteris-Black 2004; Musolff 2006; Oster 2010; David etal. 2014; Stickles et al. 2016; Petruck 2016; Koller et al. 2008; L'Hote 2014; Demmen et al. 2015). In critical metaphor studies (Charteris-Black 2004; Musolff 2006), researchers manually mine small corpora for metaphorical language, qualitatively assessing data for common metaphorical patterns. Other semi-automated techniques involve identifying lexical units attached to specific source domains, for example, automatically searching a corpus for lexical items associated with particular semantic domains, and then manually reviewing the data for instances of specific types of conceptual metaphors (Oster 2010; Koller et al. 2008; L'Hote 2014; Demmen et al. 2015).

In some cases, the combination of a metaphoric verb and a non-metaphoric noun is what determines the metaphoric interpretation of the sentence (Petruck 2016: 135), or collocated pairs of source and target triggers in general. Hence, fully automated approaches to metaphor identification include a focus on target and source word pairs (Shutova 2015 and citations therein), with select projects directed toward cataloguing the relationship between grammar, metaphors, and the system of conceptual metaphor (David et al. 2014; Stickles et al. 2016).

\subsection{Metaphor and grammar}

In cognitive theories of grammar, metaphor plays an important role in governing and explaining semantic patterns that contribute to the syntactic configurations structuring English and other languages (Langacker 1999, 2009; Talmy 1978; Lakoff 1990a; Goldberg 1995; Dancygier and Sweetser 2014). Dancygier and Sweetser 
(2014: 127) (also see Moder 2010) show how the Caused-Motion construction (Goldberg 1995), consisting of Subject Verb Theme-NP Path, encodes a starting point, path, and endpoint of motion as in (21):

(21) They dragged Joe out of the hole. (Dancygier and Sweetser 2014: 127)

When the verb drag, which encodes explicit caused-motion, is replaced with the non-motion, usually intransitive laugh, the sentence retains a sense of motion; however, in this case, the motion is metaphorical. Joe's 'movement' is from a state of depression to a state beyond depression in (22):

(22) They laughed Joe out of the depression. (Dancygier and Sweetser 2014: 127)

Because STATES, like depression, are metaphorically understood as LOCATIONS in space, and CHANGE in STATE is metaphorically understood as CHANGE in LOCATION, the verb laugh can be used transitively to describe the force that results in the change in state.

COMMUNICATION, as a target domain, draws on a related source domain, OBJECT TRANSFER, in this case, from speaker to listener, SENDER to RECIPIENT (Reddy 1979). Thus, the same syntactic construction can be used to describe events of communication as in (23), in which traditional verbs of communication fill the verb slot:

(23) The White House press secretary told/communicated/conveyed/yelled the news to the press.

But, so too can prototypical verbs of literal motion, liquid-motion in (24):

(24) The White House press secretary leaked the news to the media.

A liquid-motion verb like leak can be used in this construction because communication is metaphorically understood as physical transfer. In fact, quite a few verbs of liquid motion function similarly: spew, spill, drip, trickle, etc., demonstrating the productivity of the metaphor. Whether lexicalized with prototypical communication verbs, as in (23), or a verb of explicit motion as in (24), the construction activates the same CONDUIT metaphor in which COMMUNICATION is understood as OBJECT TRANSFER (cf. David 2016, Ch 4, for a discussion of the interaction between constructional and lexical metaphor activation). Target domains (whether they be STATES of EMOTION or COMMUNICATION) that are structured by the same source domain (OBJECT-TRANSFER) are all equally able to participate in the Caused-Motion construction. 


\subsection{Deep dive into discrete constructions}

Particular grammatical positions prompt particular roles in metaphorical construal (Croft 1993: 355, Dancygier and Sweetser 2014: 134). This is true in a basic, literal copular construction (cf. Mikkelsen 2005), where the predicational material occurs after the copula (Jane is a dancer, not A dancer is Jane). Metaphorical copular constructions are no different, as in life is a journey. As noted by Dancygier and Sweetser (2014: 134), the reverse ordering - a journey is life - is grammatical, but does not make sense as a metaphorical construction absent context because the intended source domain in this sequence, LIFE, is an abstract concept, and cannot be used as a grounding mechanism to understand the more concrete frame of a journey, at least not in any conventionalized usage pattern. Because source domains are, for the most part, experiential in nature (Lakoff and Johnson 1980: Ch. 12, 1999), they tend to encode concrete information which serves as the predicational material used to understand the more abstract, non-experiential target domain, hence the conventionalized reporting of conceptual metaphors as TARGET IS SOURCE.

Sullivan $(2009,2013)$ argues that the same conceptual dependency - target domain dependent on source domain - explains broad regularities concerning which grammatical slots are filled by source and target domain vocabulary in isolated constructions when both domains are overtly expressed. In general, Sullivan (2013: 63) contends there are strong tendencies for attributive adjectives to be source domain triggers while the nouns they modify evoke the target domain. In her example, blood-stained wealth (money gained through criminal means, not bills soaked in actual blood), the modifying adjective blood-stained elaborates the source domain of the metaphor IMMORALITY IS FILTH (converse of MORALITY IS CLEANLINESS, i.e. clean vs. dirty money) (Sullivan 2013: 63; Kövecses 2010). Sullivan explains the connection between modifiers and source domains through dependency patterns noted in literal language. Her explanation rests on observations of trajector-landmark dependency relations within the Cognitive Grammar framework.

In literal language, Langacker $(1987,1991)$ posits that in modification constructions, there is an asymmetry of conceptual dependency. The head is more semantically autonomous whereas the modifier is more dependent. He uses the contrast between big elephant vs. big molecule - in each phrase it is the noun that determines the size of the scale (Langacker 1987: 285). Langacker shows the reverse is true for predicate-argument, V-N, constructions - the verb (head) is conceptually and semantically dependent on the noun: In open the book or open your eye, comprehension of the associated motion indexed by the verb depends on specific knowledge about the opened object (we can only simulate an 
opening event accurately through our understanding of detailed information about the argument-book-opening involves a completely different motor program than does eye-opening). In each case of predication, whether adjective or verb, the semantically predicated information (OPEN and BIG) is dependent on the modified argument. ${ }^{1}$

However, not all modifiers are alike. At a broad level, modifiers can be divided into two types: 'domain' and 'attributive' (sometimes called 'relational' and 'qualitative' (cf. Gunkel and Zifonun 2008: 283). Domain adjectives are predominantly formed with non-Germanic suffixes, often of Latin origin, i.e. -al, -an, -ary, -ic, etc. (Gunkel and Zifonun 2008: 284). However, these same suffixes and their allomorphs (Huddleston and Pullum 2002: 1707-1712) can also be used to form attributive adjectives. As Langacker notes (1991), attributive modifiers, as predicates, are semantically dependent on the nouns they modify red does not mean the same thing in red pen and red army ${ }^{2}$. But domain modifiers are semantically independent - the meaning of religious in religious leader is basically the same as the meaning of religious in religious book. The job of a domain adjective is to specify a (usually abstract) domain to which a concept or entity belongs, to reference the general category by which we can evaluate the noun. Sullivan (2013, Ch. 5), discussing domain adjectives, introduces the phrase moral wealth (a phrase that refers to high level of morality (from MORALITY IS MONEY based on the MORAL ACCOUNTING metaphor [Lakoff 1997]). In moral wealth, moral does not function as predicational material; the phrase does not mean wealth is moral. We understand moral wealth as a certain type of (metaphorical) wealth, in contrast to personal, material, national, mineral, etc. In phrases like this which include domain modifiers, the adjective position aligns with the target domain, and the modified noun, with the source. (In this case, wealth elaborates the MONEY source domain.) So unlike attributive adjective constructions, which align with a source-target ordering, domain adjective constructions warrant a target-source alignment.

Based on these observations, we should expect particular alignment patterns between source and target domain triggers and the syntactic constructions they fill. These patterns extend beyond A-N constructions to others. Because source-target

\footnotetext{
1 As a reviewer notes, this generalization is not without problem. Some transitive verbs have a greater conceptual independence because of the more predictable nature of their objects. For example, a verb like kill, used literally, specifies a living entity, and is thus, perhaps less conceptually dependent on its object than a motion verb like open.

2 This conceptual dependence is also oversimplified by Langacker as noted by the same reviewer. In a phrase like sad movie, the meaning of sad isn't solely dependent on the meaning of movie, but also on the conceptual knowledge that sad references the movie viewer's reaction to its context.
} 
alignment is conceptual (and only cued by the syntax), in each case, the predicating/attributive modifier position, whether a noun, adjective, or verb, is expected to be filled by the source trigger and the modified noun position by the target trigger. Likewise, the alignment between domain-modifier and target trigger can be extended into other syntactic constructions. For example, domain specifiers often fill the first slot in N-N compounds and the possessor position in possessive constructions (Gunkel and Zifonun 2008: 284), i.e. education problems, educational problems, education's problems, problems of education. The semantic and conceptual relations encoded in simple syntactic constructions allow a forecast of how source and target triggers will combine. Corpus data involving the same pairs of source and target triggers, thus, provide the input to test predictions about the lexicalization patterns of conceptual metaphors.

\section{Methodology: Data collection and coding}

In order to examine the lexicalization patterns of pairs of source and target lexis, this study draws on already identified metaphorical lexis from Lederer (2016), in which a robust corpus of economic discourse was built from the business and finance sections of The Economist magazine. This 2,084,650 token corpus of The Economist data, taken from articles in the business and finance sections of issues published between 2008 and 2015, was compiled through the Sketch Engine interface (Kilgarriff et al. 2014). In Lederer (2016) source domain lexis was gathered by pulling common words associated with three robust source domains used to structure economic metaphors: WEATHER, SHIP, and (AILING) BODY. Candidate lexis like storm, wave, channel, and disease was searched in The Economist corpus and then evaluated for its metaphoricity in relationship to the economy.

The term 'source trigger' is used to indicate any lexical item in the specialized corpus that evokes one or more relevant source domains. Many words can function as trigger lexemes. Some are words very closely tied to a source domain frame; for example, the phrase life support is directly tied to our understanding of hospitals, emergency rooms, and very sick patients, and can be used to activate the metaphor ECONOMY IS (AILING) HUMAN BODY. Other words, however, activate one source domain, but that source domain structures more than one target. This would be the case for a word like circulation, which can be used to describe the movement of money, MONEY IS LIQUID, but can also be used as a source domain trigger for a different metaphor like IMMIGRATION IS THE FLOW OF WATER. Thus circulation is only counted as a trigger when used in metaphorical description of the economy. 
The 84 selected source triggers identified in The Economist corpus were used metaphorically at a significant rate (over $20 \%$ of use metaphorical), and in some cases, deemed to be 'key' lexical units (Ahmad 2005), meaning that they have a higher rate of occurrence in economic discourse than in basic English (Lederer 2016). Source triggers from the domains of SHIP, WEATHER, and HEALTH included lemmas like sail, storm, channel, conditions, freeze, cloudy, turbulent, ailing, and health. The list of target triggers used in this study includes the 12 most frequent target triggers that appear in the top 100 most frequent words in The Economist corpus (bank, invest, market, firm, debt, finance, rate, price, capital, growth, economy, money). The permutation of the 12 target triggers with the 84 source triggers yielded 2016 ordered combinatorial pairings, i.e. investment freeze and turbulent market. These lexical pairings were evaluated within five syntactic constructions in the Corpus of Contemporary American English (Davies 2008-present): NP-of-NP (captain of finance; wave of capital), A-NP (economic headwinds; ailing economy), N-N compound (debt bubble; bubble market) V-NP (steer the economy), and $\mathrm{X}$ is $\mathrm{Y}$ (the economy is a sinking ship).

\subsection{Lexicosyntactic alignment}

Ordered searches ensured that source and target triggers were inputted into both positions of each construction, resulting in a total of 10 possible alignments: NP(Source)-of-NP(Target), NP(Target)-of-NP(Source), A(Target)-NP (Source), A(Source)-NP (Target), N(Target)- N(Source), N(Source)-N(Target), V(Source)-NP(Target), V(Target)-NP((Source), $\mathrm{X}$ is Y (Target is Source), X is Y (Source is Target). Triggers always filled head roles in the case of complex subconstituents.

A total of 12,816 manual searches (McEnery and Wilson 2001) in COCA were carried out systematically by inputting (to COCA's search interface) each lexical pair in both orders (i.e. financ ${ }^{\star}$ health*; health* financ ${ }^{\star}$ ), allowing for up to five intervening wild cards (finance ${ }^{\star \star \star \star \star \star}$ health ${ }^{\star}$ ) in order to permit intermediate words to occur between the source and target triggers, i.e. steer (VERB-SOURCE) the (WILDCARD) American (WILDCARD) economy (NOUN-TARGET). Concordance line results from COCA were reviewed one by one and, when an example fit one of the ten syntactic configurations, the token was tagged into the appropriate syntactic construction grouping. This methodology allowed annotators to bypass COCA's automated part of speech tagging algorithm. 


\subsection{Tagging metaphors}

Coding for metaphorical use followed the MIP(VU) method, a commonly accepted standard for metaphor identification (Pragglejaz Group 2007; Steen et al. 2010). This method, applied to all searched collocations involves (1) reading each concordance line corresponding to collocation searches, (2) establishing the contextual meaning of the collocation in question and (3) marking the phrase as metaphorical when it is not used to signal a more basic, literal referent. For example, a floating market would not be collected as a metaphorical phrase when it references a farmers' market in Southeast Asia built on floating platforms; however, a floating market, used to reference a numerical index of a particular economic market, would be marked as metaphorical. Only tokens that fit the syntactic construction and were used in metaphorical reference to the economy were logged as metaphorical hits. Two annotators agreed on all tokens tagged as metaphorical.

This procedure, totaling approximately 13,000 manual searches in COCA, and subsequent coding process, resulted in a database of 9,001 phrasal tokens representing 331 out of 1,008 possible pairing types.

\section{Results: Syntactic distribution}

Sullivan's $(2007,2013)$ predictions that target triggers will be realized in semantically autonomous positions is confirmed by the corpus collocations patterns. This section includes Sullivan's predictions for each of the five syntactic configurations tested and the corresponding type and token counts for each category.

\subsection{A-NP prediction}

On the surface, the A-NP construction seems to show no preference for source-target ordering alignment; results show 86 pairings in which the source trigger filled the adjective position and the target trigger filled the head noun (A(S)-N(T)) and 96 pairings in which the target trigger filled the adjective position and the source trigger filled the head noun ( $\mathrm{A}(\mathrm{T})-\mathrm{N}(\mathrm{S}))$. But, as outlined in (\$2.5), adjectives, as modifiers, serve two separate functions -to specify domains (domain-specifying) and to encode attributive material (attributive-modifiers). Given the same pair of triggers, Sullivan predicts that the former type will be lexicalized via the target domain and the latter by the source. This tendency is overwhelmingly confirmed in 
the corpus data as illustrated in Table 2. Eighty-six pairings follow the AttributiveAdjective(S)-N(T) alignment, while there are no instances in which the attributive adjective is lexicalized with a source trigger (Attributive-Adjective(T)-N(S)). Ninetyone pairings follow the Domain-Adjective(T)-N(S) alignment, while there is only one instance in which the domain adjective is lexicalized with a source trigger (Domain-Adjective(S)-N(T)).

Table 2: Source-target alignment in A-NP constructions.

\begin{tabular}{llrrl}
\hline Construction & Sullivan's Prediction & $\begin{array}{r}\text { Type } \\
\text { Count }\end{array}$ & $\begin{array}{r}\text { Token } \\
\text { Count }\end{array}$ & Example collocations \\
\hline A (attributive)(T)-N(S) & No & 0 & 0 & \\
A(attributive)(S)-N(T) & Yes & 86 & 1,091 & $\begin{array}{l}\text { floating rate } \\
\text { sinking stock prices }\end{array}$ \\
& & & & $\begin{array}{l}\text { sick and dying banks } \\
\text { oceanic market } \\
\text { economic flow } \\
\text { f(domain)(S)-N(T) }\end{array}$ \\
No & Yes & 1 & 1 & 4,088 incial aches and pain \\
A(domain)(T)-N (S) & & 91 & &
\end{tabular}

\subsection{V-NP prediction}

Since verbs, like attributive adjectives, provide predicational material about their arguments, according to Sullivan's theory, we should expect the verb to be lexicalized with a source, not target trigger. Eighty-three pairings follow the $\mathrm{V}(\mathrm{S})-\mathrm{N}(\mathrm{T})$ alignment, while there are only seven pair types in which the verb is lexicalized with a target trigger $(\mathrm{V}(\mathrm{T})-\mathrm{N}(\mathrm{S}))$. Total counts are shown in Table 3.

Table 3: Source-target alignment in A-NP constructions.

\begin{tabular}{llccl}
\hline Construction & $\begin{array}{l}\text { Sullivan's } \\
\text { Prediction }\end{array}$ & Type Count & Token Count & Example collocations \\
\hline $\mathrm{V}(\mathrm{T})-\mathrm{NP}(\mathrm{S})$ & no & 7 & 27 & $\begin{array}{l}\text { rate US business conditions } \\
\text { invest those incremental } \\
\text { revenue streams }\end{array}$ \\
$\mathrm{V}(\mathrm{S})-\mathrm{NP}(\mathrm{T})$ & yes & 83 & 858 & $\begin{array}{l}\text { flood money } \\
\text { cure their debt } \\
\text { sink a lot of investment }\end{array}$ \\
Total & 90 & 885 & \\
\hline
\end{tabular}




\section{3 $\mathrm{N}-\mathrm{N}$ prediction}

Sullivan's predictions extend to N-N compounds. Noun compounds are complex in their internal semantic relations given the array of possible relationships expressed (cf. Ryder 1994). However, in metaphorical compounds that include one source and one target trigger, these are limited to two types. In one case, the first slot in N-N compounds is a domain modifier, as in job title (literal) or economy climate (metaphorical), while in the other cases, the first noun is filled by an argument and the second by a (deverbal) nominal, which encodes predicational material, as in car race (literal) or money flow (metaphorical). Thus, based on the notion that source domains provide predicational material for the corresponding target, we should predict a N(T)-N(S) alignment for both types of $\mathrm{N}-\mathrm{N}$ compounds, but for different reasons. Compounds with domain-specifying nouns followed by their categorical constituent should mimic the DomainAdjective(T)-N(S) alignment. Likewise, compounds of argument nouns followed by predicate-encoding (deverbal) nouns should also realize the source-domain trigger in the second slot, since source domains provide the predicational material. By evoking the source domain, the syntactic head, in both cases, carries the metaphorical load. The target trigger, is then relegated to a secondary, dependent syntactic role. The source domain must be syntactically prominent. The prediction is supported in the corpus data as illustrated in Table 4.

Table 4: Source-target alignment in N-N compounds.

\begin{tabular}{llrrl}
\hline Construction & Sullivan's Prediction & Type Count & Token Count & Example Collocation \\
\hline $\mathrm{N}(\mathrm{T})-\mathrm{N}(\mathrm{S})$ & yes & 90 & 1114 & $\begin{array}{l}\text { investment waters } \\
\text { price freeze } \\
\text { bubble economy } \\
\text { recovery money }\end{array}$ \\
$\mathrm{N}(\mathrm{S})-\mathrm{N}(\mathrm{T})$ & no & 8 & 99 & \\
\hline
\end{tabular}

Ninety pairings follow the $\mathrm{N}(\mathrm{T}) \mathrm{N}(\mathrm{S})$ alignment, while there are only eight instances in which the first noun is lexicalized with a source trigger $(\mathrm{N}(\mathrm{S})-\mathrm{N}(\mathrm{T})$ ).

\subsubsection{Exceptions}

There are eight instances of the minority pattern in which the first noun slot is lexicalized with source domain language. The use of bubble or recovery the first 
noun position account for the vast majority of these tokens (87/99). This inversion of the typical pattern sheds light on how predicational lexis can, once established, shift over time to specify a discrete, categorical domain. Market, economic, real estate bubbles are over-valuations of assets. At a conceptual level, the metaphorical term bubble evokes the visual presentation of the parabolic nature of a rapid increase and subsequent decrease in valuation. Market bubble exhibits the expected order in which the source domain, as predicational material, is lexicalized in the second noun slot (The market is a bubble) as in (24)-(26):

(24) If there were too many office buildings and shopping malls built in Thailand, it was for pretty much the same reason that 10 years ago there were too many office buildings and shopping malls built in Texas - runaway financial system, bad regulation, and a little bit of - more than a little bit of a market bubble. It's not something that is completely novel; it's not something that should cause us to think, oh, my God, the whole system is about to fall apart.

(25) But the collapse of Japan's spectacular real estate and stock market bubble in 1990 dealt a crippling blow to those institutions.

(26) The Japanese bubble burst more than a decade ago, and the economy is still reeling. You can blame inept policymakers for that. Disdain for speculation and for unearned gain has been a common thread in popular discussion of market bubbles ever since. It isn't an entirely misguided attitude.

Over time, however, the word bubble has become part of standard economic jargon, signaling a repeated pattern in asset fluctuation. The bubble pattern is pervasive enough to now constitute a market type. That is, economic markets can now be classified as bubbles, not just predicated to be bubbles. In this type of semantic broadening, we see bubble extend from a market attribute to a market type, allowing it to fill a domain-specifying syntactic position as in (27) and (28):

(27) Panama is another market that continues to expand, thanks to the cash cow that is the Panama Canal. Many of the bubble markets are now down 50 percent or more. While they won't likely fully recover for some time still, several may make sense today for investing for rental rather than capital appreciation. 
(28) ...prices have got to come back down in line with income, and I think that in some of these bubble markets. That's just going to be whether it happens fast or slow, they got to come back down in line with incomes.

(Bubble commonly occurs with a plural noun. We take this as further evidence that bubble has shifted to a domain-specifier.) It must be noted that both instances, market bubble and bubble market, are metaphorical. A market bubble is not a bubble floating in a market, and a bubble market is not a store that sells bubbles. Both constructions retain their metaphoricity and, arguably, their conceptual link to metaphorical models of the economy, yet the shift from predicate- to domain-specifier function of the source trigger is due to practices within the speech community, a complex example of the interaction between conceptual metaphor and semantic shift over time.

\subsection{NP-of-NP prediction}

The domain-specifier pattern of A-NP constructions and N-N compounds extends to relationships of possession, i.e. job title, title of job (literal) and economy climate, climate of the economy (metaphorical) In N-of-N sequences, the second noun typically fills the possessor role, semantically encoding the domain of belonging. As an illustration of the same semantic pattern, we should expect the target trigger to fill the possessor role, the second noun slot. The prediction is supported in the corpus data as illustrated in Table 5. One hundred twenty-six pairings follow the NP(S)-of-NP (T) alignment, while there are only five pairings (eight tokens) in which the first noun is lexicalized with a target trigger, the $\mathrm{NP}(\mathrm{T})$-of-NP(S) configuration.

Table 5: Source-target alignment in NP-of-NP compounds.

\begin{tabular}{llrrl}
\hline Construction & $\begin{array}{l}\text { Sullivan's } \\
\text { Prediction }\end{array}$ & Type Count & Token Count & Example Collocation \\
\hline $\mathrm{NP}(\mathrm{T})$-of-NP(S) & no & 5 & 8 & $\begin{array}{l}\text { rate of a normal recovery } \\
\text { growth of international }\end{array}$ \\
$\mathrm{NP}(\mathrm{S})$-of-NP(T) & yes & 126 & 1010 & $\begin{array}{l}\text { currency flows } \\
\text { sea of money } \\
\text { vagaries of the economy }\end{array}$ \\
\hline
\end{tabular}

Instances of the minority pattern in which the target trigger fills the head position, the first noun slot, are explained through two subpatterns. In some cases, source domain language like (cash) flow in rate of (cash) flow, has been 
regularized to reference specific economic measures or institutionalized concepts, as is the case with bubble. In these tokens the source domain, not the target, serves as the domain specifier. In the second subpattern, exemplified through collocations like firms of health, the source trigger is attributional in nature. Health predicates information about the (positive) performance of a given financial institution.

\section{5 $X$ is $Y$}

On a rare occasion, conceptual metaphors for the economy are lexicalized in copula construction. Predicates in copular clauses provide information about their subjects (Halliday 1967; Akmajian 1979: 162-165), mirroring the role source domains play in establishing the conceptual architecture to structure the target. In all save one of the 33 cases from the data, the source domain is realized in the predicate as would be expected. Specific source triggers appear mostly as predicate adjectives (market is healthy), occasionally as a predicate nominal (market is a bubble), and, in one case, within a prepositional phrase (on life support). Total counts are shown in Table 6.

Table 6: Source-target alignment in $\mathrm{X}$ is $\mathrm{Y}$ (copula) constructions.

\begin{tabular}{|c|c|c|c|c|}
\hline Construction & $\begin{array}{l}\text { Sullivan's } \\
\text { Prediction }\end{array}$ & Type Count & Token Count & Example Collocation \\
\hline $\begin{array}{l}\text { Copula } \mathrm{X} \text { is } \mathrm{Y} \\
\text { (Target is Source) }\end{array}$ & yes & 32 & 174 & $\begin{array}{l}\text { markets are frozen } \\
\text { prices are frothy }\end{array}$ \\
\hline $\begin{array}{l}\text { Copula } \mathrm{X} \text { is } \mathrm{Y} \\
\text { (Source is Target) }\end{array}$ & no & 1 & 1 & $\begin{array}{l}\text { Remaining cloud is } \\
\text { corporate debt }\end{array}$ \\
\hline
\end{tabular}

The lone counterexample to the target is source ordering of the copula construction, the sole remaining cloud is corporate debt, is specificational in nature (cf. Mikkelsen 2005); the predicate (target) is classified though a source concept.

\subsection{Interim summary}

The asymmetrical distribution of source and target constructional alignment throughout the data is summarized in Figure 2; source domains lexicalize predicational material which corresponds to specific syntactic positions. These 
Total Number of Source and Target Domain Pairs

Per Construction

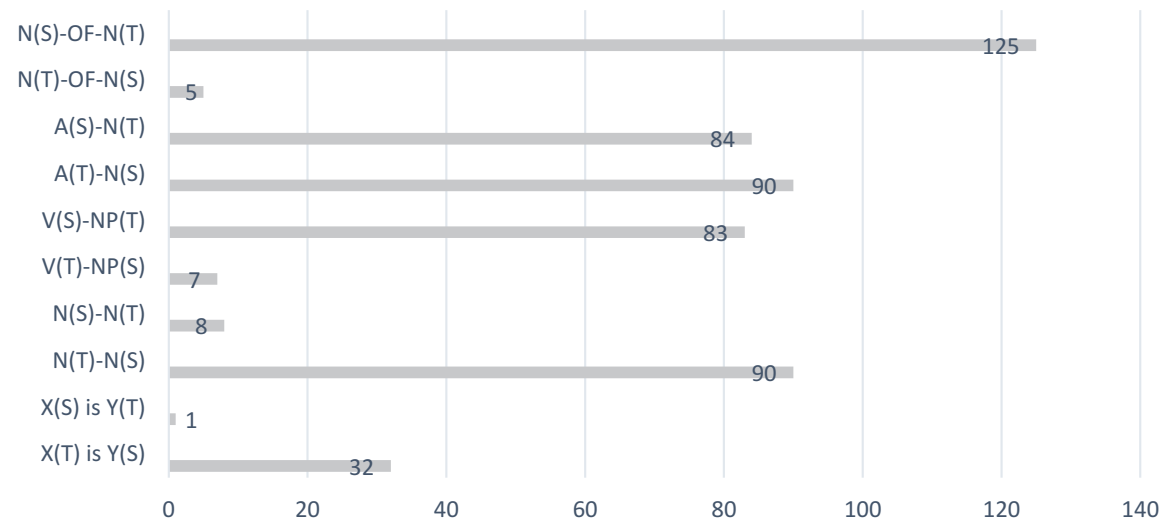

Figure 2: Source-target type counts across five syntactic constructions.

results are consistent with findings from other corpus studies showing that verbs and adjectives account for a large proportion of metaphorical expressions observed in natural language data (cf. Cameron 2003; Deignan 2005; Pragglejaz Group 2007; Shutova and Teufel 2010). The few exceptions to the very strong tendencies in the data come from lexemes that have been recruited into economic jargon such that they have shifted from simply encoding a nuanced concept to establishing a categorical domain., i.e. recovery, bubble, etc. The strong asymmetrical syntactic patterns in metaphorical lexicalization indicate that metaphoric construal is not generated by a simple pairing between a source and target trigger, nor a simple frame mismatch between two lexical items (as noted in Sullivan 2016: 151), metaphorical construal is based on a unidirectional mapping from source to target domain. Likewise, positional alignment between syntactic constituent and domain type indicates that the semantic function of syntactic positions plays a crucial role in the lexicalization of conceptual metaphors.

Patterns of syntactic distribution reflect the predicational function of the source domain. These strong tendencies can inform predictions as to how source and target lexis will be encoded across the five construction and guide automated tagging systems (cf. Shutova 2015). Of the 530 pairing configurations, 95.8\% (508/530) of type and 98.4\% (8335/8471) of token counts follow the expected alignment. Table 7 illustrates the prediction for one source-target pair. 
Table 7: Illustration of alignment predictions for one sourcetarget pair.

\begin{tabular}{ll}
\hline Target Lexis & Source Lexis \\
\hline economy & forecast \\
A(attributive)(S)-N(T) & forecasted economy \\
$A($ domain) $(T)-N(S)$ & economic forecast \\
$V(S)-N P(T)$ & forecast the economy \\
$N(T)-N(S)$ & economy forecast \\
$N P(S)-o f-N P(T)$ & forecast of the economy \\
$X(T)$ is $Y(S)$ & the economy is forecasted \\
\hline
\end{tabular}

Reversals of the expected alignment result mostly in nonmetaphorical phraseology (marketed flood, flood market, market the flood, market of the flood, the flood is marketed, invested flood, flood investment, invest in the flood, flood investment, investment of the flood, etc.) These findings have important consequences for the meaningful identification of metaphorical language, both manual and automated. If systems can tag lemmas as belonging to pre-specified source and target domains in the taxonomy, they can predict their distribution when used in combination across these constructions. The corollary is also possible; when used in combination, the system can automatically categorize them as source or target lemmas.

\section{Additional parameters of lexicalization}

This second section of the paper covers results from simple measures which address four important aspects of metaphorical lexicalization and entrenchment (cf. Langacker 1987: 100): (1) Syntactic rigidity - which source-target pairs occur in multiple syntactic configurations? (2) conventionality - given the lexis examined, what metaphorical phraseology is most frequent? (3) Combinability which source triggers are most permissive in their ability to combine with target triggers and why? (4) Distributional asymmetries - given the same pair of source and target triggers, why are certain orderings more frequent than others? These findings construct a picture of the interplay between the conceptual model governing economic thinking and the standardization of economic jargon. What falls out is a cline of standardization and creativity - the same conceptual metaphors are activated through both set metaphorical phraseology and novel, infrequent pairings of source and target triggers. 


\subsection{Syntactic rigidity}

Syntactic rigidity is one way to measure economic phraseology and the co-selection of source-target pairings. Another way to think about this concept is to gage which pairs are the most syntactically fluid - which pairings have the widest distribution across the syntactic constructions, and which seem to be frozen on one particular configuration. Lexical co-selection can be examined from several angles including consecutive sequences, n-grams ( $a$ lot of) (Cheng 2012: 72) and lexical bundles (you know what I mean) (Biber et al. 1999: 990), heads and dependents (play a role) (Cheng et al. 2009), colligation of content and function words (in some cases; in both cases; in most cases) (Stubbs 2002: 65), clause collocations (The reason ... is because) (Hunston 2002: 75), genre and register specific patterns (Scott and Tribble 2006, Ooi 2008), and, finally, sequences of variable constituency, 'concgrams', (risk management; management of risk) (Cheng et al. 2006, 2009). Sourcetarget pairings are best characterized through this last category, concgrams, since their co-selection can vary in syntactic configuration.

A large group of source-target/target-source collocations occur in only one syntactic pattern within the data probed: In COCA, 204 (20.2\%) of all 1,008 possible pairings occur in one configuration only; $8.3 \%$ occur in two syntactic constructions. Only six pairings are found in all five configurations (the majority of possible source-target trigger pairings (785) do not occur at all, see Figure 3). This distribution suggests that metaphorical phraseology is variable in nature: Most source-target pairing that do occur in COCA are linked to one construction, while a small minority are syntactically fluid.

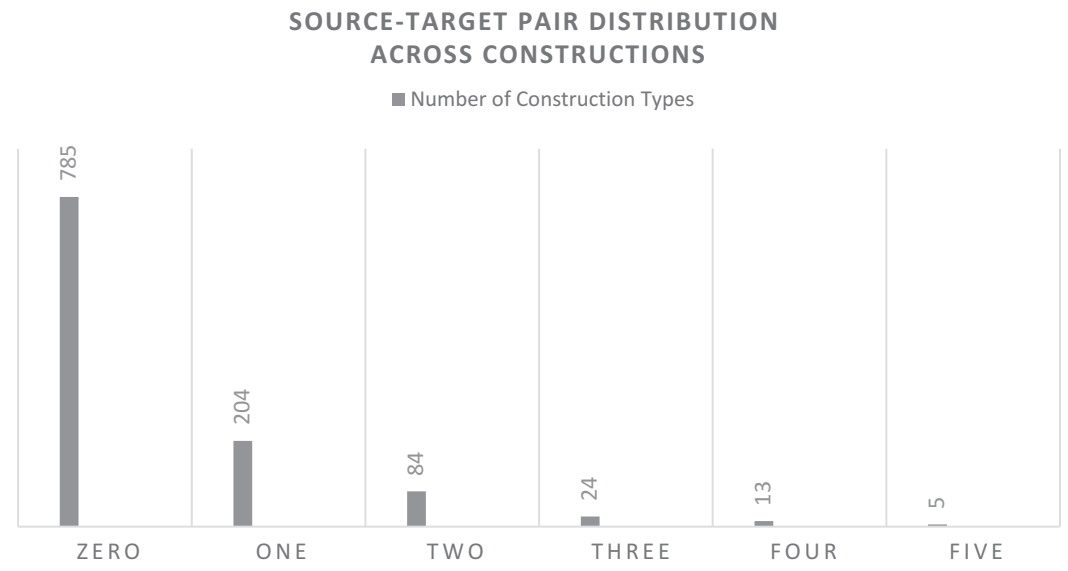

Figure 3: Quantity of syntactic participation for source-target pairs. 


\subsection{Conventionality}

A second measurement of lexicalization relies on frequency statistics as an indication of conventionality in a speech community (Cheng 2012). Conventionality can, in some instances, correlate with idiomaticity (Gibbs 1984; Gibbs and Nayak 1989). The identification of the most frequent sourcetarget pairings for any given metaphorical model is an additional important metric for not only understanding metaphor lexicalization but for cataloguing metaphorical phraseology by domain. On one end, highly frequent collocations of set source and target triggers can be considered as common fixed or semifixed phrases (probably learned and stored as units [Sinclair 1991, 1994]). On the other end, more creative and novel collocations will be less frequent in corpus data, and, thus, not considered conventionalized, metaphorical jargon. Along the continuum, top pairings like economic recovery and market conditions occur in hundreds of examples, while other phrases are common, but not as prolific, i.e. forecast growth. This common jargon occurs in tandem with novel collocations found in just one or two corpus tokens.

These results confirm Gibbs's (1984) observation that metaphorical expressions are spread along a continuum from, as Gibbs characterizes them, highly 'conventional', lexicalized metaphors to entirely 'novel' and creative ones, (sometimes referred to as 'dead' and 'alive' or 'conventional' and 'innovative' [cf. Traugott 1985: 33]). Conventionality (as gaged by frequency) allows for a more detailed picture of how conceptual metaphors are lexicalized and then adopted into speech communities as set phraseologies with different rates of usage.

\subsection{Distributional coverage}

'Combinability' measures the likelihood of a word or word class to appear in a recurrent word pattern (Eeg-Olofsson and Altenberg 1996). The grammatical status of a root inevitably affects its combinability score (Eeg-Olofsson and Altenberg 1996: 103). Verb roots like flow, which can manifest as a verb (flow), a noun (flow), and a modifier (flowing), are able to fill more syntactic positions than those roots which are morphologically restricted. Likewise, roots which combine with more derivational suffixes have an increased ability to appear in a larger variety of phrasal units. However, economic corpus data suggest that factors beyond just morphological variation contribute to a particular trigger's rate and spread of usage. Corroborating past observations (cf. Winter 2016), frequency of metaphorical use in economic discourse overall correlates to a source trigger's combinability score $(r=0.59, p<0.05, n=48)$. On the other hand, neither a trigger's metaphoricity 
rate $(\mathrm{r}=0.18, \mathrm{p}<0.05, \mathrm{n}=48)$ (given all instances, what percentage of token are metaphorical in economic discourse) nor keyness score $(\mathrm{r}=0.17, \mathrm{p}<0.05, \mathrm{n}=48)$ (rate of usage in economic versus basic contexts) correspond to a source trigger's permissibility with multiple target triggers. (Keyness calculated based on rate of occurrence in The Economist corpus compared to the Academic section of COCA; metaphoricity is rate of metaphorical use in The Economist corpus.)

A given lexeme's frequency in economic discourse and its increased combinability is a bidirectional correlative, not causal, relationship. Combinability and overall frequency of source triggers necessarily involve lexical semantics. Certain source domain concepts (and their associated triggers) play an outsized role in economic theory and discussion, and thus, pair with a wider range of target triggers. The top ten most widely distributed source triggers (flow, freeze, recover, sink, wave, climate, health, forecast, bubble, conditions) represent economic concepts central to the discussion of the economy. They are mostly nonspecific, abstract concepts, conventionalized in the economic literature because they evoke widely discussed theoretical notions. Flow, freeze, wave and channel are closely tied to the domain of WATER, central to the discussion of currency. Health and recovery are fundamental abstract concepts that index the (AILING) BODY frame. Forecast and conditions, similarly abstract, are concepts central to the WEATHER source domain, but do not reference concrete elements like rain and snow. These highly distributed source triggers can be contrasted with source triggers very limited in their distribution.

The same reasoning explains why some triggers are limited to one or two pairings such as autopsy, keel, ballast, terrain and vagaries. These words participate in limited (semi-)fixed phrases in economic discourse because they reference very specific, in many cases, concrete, imageable aspects of the source frame. The precise and concrete nature of these lexemes prohibit their combinability and frequency. ${ }^{3}$ For any given source domain, we can expect, within the constellation of triggers, concrete, specific, and imageable lexis to play a more limited role in metaphor lexicalization than abstract and semantically vague triggers, which will account for more instances of lexicalization.

The observed correlation between abstractness and combinability speaks to theories of consciousness and intentionality of metaphor usage. Steen (2011), among others, makes a distinction between deliberate and non-deliberate metaphor: 'Deliberate' metaphor, he argues, is a conscious analogical construction

3 To some extent frequency and combinability may correlate with Langacker's (1987: 357) notion of 'relational' concepts encoded in verbs, adjectives, adverbs, and prepositions (more frequent) and 'non-relational' 'things' encoded in nouns (less frequent). 
between domains, and 'non-deliberate' metaphors are frequent and conventionalized collocations or lexical senses. This is certainly a controversial notion in metaphor studies (cf. Gibbs 2017: 83-84), and not the focus of the present study. What seems clear, however, based on the results outlined above, is that any attempt to divide metaphor samples within a particular conceptual mapping should not be a categorical endeavor. That is, we should not take any one specific frequency or combinability score and posit it as a threshold for conventionalization. Some frequent source-target pairings like economic health index well established theoretical notions, while others like autopsy of the economy are based on the same set of metaphorical bindings but have not conventionalized. In the middle are hundreds of source-target pairs, used more than once, but not frequently.

\subsection{Robust pairing asymmetries}

Within some frequent source-target pairings, highly asymmetrical constructional participation can be found. For example, in COCA, there are 270 tokens of financial health and only two tokens of healthy finances. Financial health is used as a gage of the financial well-being of an institution: a bank or a local or national government as in (29)-(31):

(29) The fallout can be seen in measures of the pension system's financial health.

(30) He said the city's financial health was better than indicated by the formula.

(31) The selling was also driven by concerns about the financial health of Europe's major banks and the possible effects here.

Healthy finances is used in a similar context in COCA, but only twice, as in (32):

(32) Hence healthy finances and currency stability - fundamental conditions for entering a monetary union.

Part of the explanation for these asymmetries surely rests on the genre of discourse represented in COCA. COCA's representation of economic discourse is skewed towards academic and journalistic genres focused on macroeconomic issues. Unlike financial health, mostly applied to institutions, healthy finances is 
often used to describe the financial state of an individual - a microeconomic discussion. For example, on the web, several self-help brochures include the phrase as in your guide to healthy finances and four elements to healthy finances. This latter discourse context may not be well represented in COCA. Thus, discourse genre can play a role too in the specific lexicalization pattern of a given source target pairing. Data source must be taken into account when looking at specific pairs. However, apart from discourse context, the health-finance disparity seems to mirror a larger pattern. Ordering asymmetries may also be indicative of a preference for target triggers to, when appropriate, lexicalize in domain adjective positions. Economy, as a target trigger exhibits the same asymmetry as does finance. Overwhelmingly, the two triggers are lexicalized through the A-Domain (T)-NP(S) pattern as in (33), even though the reverse ordering A-Attributive(S)-NP (T) is possible as in (34) (economic recovery $=1,207$, recovering economy $=48$; economic $\operatorname{pain}(s)=93$, painful economy $=1)$.

(33) Germany had survived its financial collapse, and everywhere economic recovery seems strong.

(34) He hailed recent statistics showing a recovering economy.

The adjectival use of economic in the A-Domain(T)-NP(Source) construction also eclipses the lemma's use in the NP(S)-of-NP(T) construction: economic health $=245$, health of the economy $=110$; economic conditions $=1184$, conditions of the economy $=9$; economic recovery $=1207$, recovery of the economy $=29$ ). Other collocations with significant asymmetries appear to be idiosyncratic and thus, do not contribute to a generalized trend. When comparing the same sourcetarget pairings across the NP(S)-of-NP(T) and $\mathrm{N}(\mathrm{T})-\mathrm{N}(\mathrm{S})$ constructions, neither construction dominates: conditions of the $\operatorname{market}(s)=7$, market conditions $=349$; health of the bank $(s)=28$, bank health $=5$; flow of investment $=46$, investment flow $=73$; flow of money $=178$, money flow $=46$.

\section{Discussion}

There are two strands of takeaways to stress based on the results of the study series. The first relates to the syntactic distribution of metaphorical pairs and the second concerns the measures of lexicalization. In regards to the former, of note is the accuracy with which semantic predication and specification mirrors metaphorical alignment: $95.8 \%$ of source-target pair types follow 
Sullivan's predictions. The results of this study also support the notion that metaphorical lexicalization is conceptual in nature, as indicated by another piece of important evidence: Metaphorical phrases are not totally fixed, but rather semi-fixed; in most cases, source target pairs allow intervening wildcards (recovery of the post-colonial plantation economy, healthy small banks) and many pairings participate in multiple syntactic configurations. This lexical flexibility shows that these pairings are not completely frozen, memorized collocation patterns.

This is not to say that specific words do not matter. Certain collocations that at first appear similar, do not seem to be synonymous. One explanation for minute lexical variation has to do with conceptual inferences. When it comes to metaphorical collocation patterns, related terms show unequal frequency patterns. For example, when discussing business and finance, speakers use cash flow more frequently than cash stream, but when discussing investment, speakers use income stream and not income flow (Lederer 2016: 545). Flow and stream mean the same thing, more or less, but they do not equally participate in economic jargon. Frequency differentials can sometimes be explained through source domain reasoning patterns (Musolff, 2006). In this specific case, they illustrate interesting properties of how money is metaphorically understood as liquid - cash flows around the world relatively unimpeded. Income, however, is assumed to exhibit unidirectional movement - from investment or job to investor or worker. Thus, the movement of income is more like a stream -flowing from origin to destination in one direction only.

Sullivan (2013, 2016: 157-158) explains these conceptually-based lexical asymmetries through semantic frames. She offers the contrast between the common use of bright to mean happy, as in bright outlook, and the nonexistent use of brilliant to express the same meaning - brilliant outlook does not mean 'happy outlook'. On the other hand, brilliant (and bright) can be used to signal intelligence, as in bright child or brilliant idea. She explains that while bright, in its literal sense, is used to modify the location, a light space, e.g. bright room, brilliant is used to modify sources of light (brilliant star) not locations that are light. Because states like happiness are understood as locations (STATES ARE LOCATIONS), they can be modified with location-denoting predicates like bright, but not with words that modify light sources such as brilliant. On the other hand, intelligence is metaphorically understood as an object (MIND IS A CONTAINER; IDEAS ARE OBJECTS), not as a state and, thus, not as a location. Therefore, both brilliant and bright are able to express intelligence since, in their literal use, they can both modify objects, as in bright lightbulb and brilliant star. As Sullivan's example illustrates, seemly idiosyncratic metaphorical lexicalization patterns are often motivated by the conceptual compatibility between nuanced reasoning 
about the source object or movement and the resulting target concept (see Lakoff 1990b and Lakoff 1993 for a detailed discussion of the Invariance Principle).

\subsection{Metaphoricity}

Dunn (2011: 53) proposes that grammatical encoding can affect judgments of metaphoricity. For example, he hypothesizes that a metaphor encoded as a nominal predicate in a copula construction: This unrequited love has become an empty bottle is more explicitly metaphorical than a similar expression in which the metaphor is encoded in a verbal predicate: This unrequited love has swallowed up my sanity. In fact, a quite extensive literature focuses on metaphorical constructions in which an established conceptual metaphor or a novel blend is lexicalized through a subject-predicate sequence (cf. Love is a journey) (see Moder 2010). But the results of the present study show, in fact, that the vast majority of lexicalization patterns are encoded within syntactic subjects or predicates (A-NP, NP-of-NP, N-N, V-N) not across syntactic subjects and predicates (X is $\mathrm{Y}$ ), (see Figure 2). Source-target pairings are particularly interesting because they are not necessarily recognized as overtly metaphorical by speakers, especially given their constituent-internal nature. NP- (stormy economy) and VP- (forecast growth) internal co-selection is clearly more hidden than is cross subject-predicate co-occurrence (the economy is ailing). This obfuscational role of grammar stands in response to metaphor skeptics like Pinker (2006, 2007). Certain patterns of grammatical encoding hide or mask conscious access to metaphor, as has been argued for other grammatical phenomenon like the encoding of reflexive predicates (cf. Talmy 2000a). The notion that grammar can in fact hide or highlight conceptual mappings reinforces the importance of paying attention to the system of metaphor and grammar, rather than basing arguments on isolated metaphorical examples. Any given instance of the lexicalization of a conceptual metaphor should not be taken as evidence for or against the "consciousness" of the metaphor; rather the system should be evaluated as whole, including complex relationships between grade of metaphoricity and frequency of metaphorical tokens. The present study shows just how time-consuming this type of evaluation is on even a limited grouping of (related) metaphors. Nevertheless, this type of work must be scaled up if we are to understand the interaction between lexical form and conceptual representation.

Even among metaphor researchers, the role of grammar is often overlooked. Steen $(2007,2011)$, for example, makes a distinction between metaphor-in-thought 
and metaphor-in-language. The fact that certain source-target pairing occur across several different constructions raises questions about Steen's rubric for the formal indicators of the deliberate nature of metaphor based on lexico-grammatical alignment. For example, if we believe that certain instances of metaphor are reflections of the conceptual system while other instances are not, we might expect a difference in the source domain lexicon used in the predicate of the copular construction (a more transparent syntactic vehicle) in comparison, to say, the attributive-adjective position in the A-NP configuration (a more disguised vehicle). However, without a priori criteria to evaluate what lexis should appear in which type of construction, we have no way to evaluate that prediction. If anything, we might expect less frequent, more novel triggers to appear exclusively in more overtly metaphorical constructions like the copular sentence. But, the results above do not support that analysis: choppy market (15 tokens) is much more frequent than the market is choppy (1 token).

\subsection{The system}

The inversion of investigative methodology - starting with conceptual mappings from the literature, identifying metaphorical lexis attached to each domain, and then searching for collocations in natural language data - is a crucial next step in metaphor research. Metaphor identification is different from metaphor analysis (Petruck 2016: 135). For the many reasons discussed in this paper, it is essential to probe corpus data systematically in the evaluation of metaphorical lexicalization process, but this process needs to be carried out in a way that is linked to the ontology of conceptual metaphors. Otherwise, we lack a conceptual explanation for linguistic behavior.

Gibbs (2017) questions the role and goals of counting metaphors. He argues that just one instance of metaphor can be very powerful in affecting reasoning, a counterargument to the idea that quantifying metaphorical lexicalization by counting instances of metaphor is a reflection of the power or salience of metaphor. Perhaps, rather than questioning the endeavor, it is the type of counting that should be scrutinized. Simply cataloguing random words in sentences as metaphorical or not does not help us understand the systemic nature of metaphor nor the lexicalization of cognitive models, but linking metaphorical phraseology to the ontology of conceptual metaphor does. By measuring lexicalization of specific source-target pairings across syntactic constructions, we can systematically catalogue conventionality and entrenchment-factors clearly related to speakers' assignment and judgment of metaphoricity. 
To this end, the study of metaphorical phraseology is one important subdomain in the investigation of the relationship between lexis and grammar. Patterns of metaphorical phraseology demonstrate the coordinated nature of the lexicon and grammar. By offering conceptual explanations for certain fixed and semi-fixed phrases, the connection between cognition and language structure becomes clearer. Metaphorical mappings feed co-selection of source and target lexis and co-selection feeds and reinforces these same metaphorical mappings, a process similar to the development of positive and negative semantic prosody associated with particular words. The results of this study yield a complex portrayal of metaphor, lexis, and grammar. Metaphorical lexicalization patterns, just like literal lexicalization patterns, cannot be explained by one and only one phenomenon (see Gibbs 2017). Discourse practice, culture, grammar, language use over time, etc. all play a role in shaping source-target pairings within topic specific genres.

\section{Conclusion}

Since the inception of Conceptual Metaphor Theory, metaphor researchers have acknowledged the unidirectional nature of conceptual mappings from source to target domain. Robust, yet limited, research has focused on the interaction between these dependency relations hypothesized at the conceptual level and syntactic dependency relations and configurations in the grammar. The contribution of this study has been to test, with natural language data, the hypothesis that predicate-denoting syntactic positions will disproportionally fill with lexical triggers that stem from the source domain within metaphorical constructions that include both a source and target lexeme. Based on considerable economic corpus data from approximately 13,000 manual searches in COCA (530 pairing configurations within five different syntactic constructions), results show $95.8 \%$ (508/530) of type and $98.4 \%(8,335 / 8,471)$ of token counts follow the expected alignment in five syntactic constructions: A-NP, NP-of-NP, N-N, V-N, and X is Y. In addition, this study has offered methods to probe lexical versatility and syntactic rigidity of source-target pairings within established conceptual metaphors. Results show source-target pairs vary considerably in their frequency, combinability, and syntactic distribution based, in part, on the semantic nature of the source-trigger in the pair and each lexeme's potential for morphological derivation. These indicators allow researchers to probe frequency differentials among sets of source and target lexis, thus enabling more detailed detection and classification of common metaphorical phrases in topical discourse. The results of the various quantitative analyses contribute to discussion and debate on the 
connection between metaphor at the conceptual level and metaphor in the grammar and lexis. Importantly, the methodology used in this paper is replicable, and can be repeated to probe patterns in other target domains in order to gain further insights into the relationship between metaphor and grammar.

Acknowledgements: Funding from the Office of Research and Sponsored Programs at San Francisco State University supported a portion of this study. I wholeheartedly thank research assistants Helena Laranetto and Guy Brown for their tireless data collection, coding, and insights. Without their dedication, this study would not be possible.

\section{Supplementary material}

There are Supplementary Materials for this article, comprising of a full list of source and target trigger lemmas, full list of source-target pairings that occur in different constructions, an ordered list of the 40 most frequent source-target pairings, and a list of the 48 most combinable source triggers. It is openly accessible via http://www.askalinguist.org/uploads/2/3/8/5/23859882/lederer_ lexico-grammatical_alignment_in_metaphor_construal_appendices_a-h.pdf

Supplemental Material: The online version of this article (DOI: 10.1515/ COG-2017-0135) offers supplementary material, available to authorized users.

\section{References}

Ahmad, Khurshid. 2005. Terminology in text. Paper presented at the Tuscan Word Centre Workshop, Siena, Italy.

Akmajian, Adrian. 1979. Aspects of the grammar of focus in English. New York: Garland.

Baker, Paul, Costas Gabrielatos, Majid Khosravinik, Michat Krzyzanowski, Tony McEnery \& Ruth Wodak. 2008. A useful methodological synergy? Combining critical discourse analysis and corpus linguistics to examine discourses of refugees and asylum seekers in the UK press. Discourse and Society 19(3). 273-306.

Biber, Douglass, Stig Johansson, Geoffrey Leech, Susan Conrad \& Edward Finegan. 1999. Longman grammar of spoken and written English. Harlow: Longman.

Boers, Frank. 1997. "No pain, no gain" in a free market rhetoric: A test for cognitive semantics? Metaphor and Symbol 12(4). 231-241.

Boers, Frank \& Murielle Demecheleer. 1997. A few metaphorical models in (western) economic discourse. In Wolf-Andreas Liebert, Gisela Redeker \& Linda R. Waugh (eds.), Discourse and perspective in cognitive linguistics, 115-129. Amsterdam: John Benjamins. 
Boroditsky, Lera. 2000. Metaphoric structuring: Understanding time through spatial metaphors. Cognition 75. 1-28.

Cameron, Lynn. 2003. Metaphor in educational discourse. London: Continuum.

Casasanto, Daniel \& Lera Boroditsky. 2008. Time in the mind: Using space to think about time. Cognition 106. 579-593.

Charteris-Black, Jonathan. 2004. Corpus approaches to critical metaphor analysis. London: Palgrave-Macmillan.

Charteris-Black, Jonathan. 2006. Britain as a container: Immigration metaphors in the 2005 election campaign. Discourse and Society 17(5). 563-581.

Cheng, Winnie. 2012. Exploring corpus linguistics, language in action. England: Routledge.

Cheng, Winnie, Chris Greaves \& Martin Warren. 2006. From n-gram to skipgram to concgram. International Journal of Corpus Linguistics 11(4). 411-433.

Cheng, Winnie, Chris Greaves, John. McH. Sinclair \& Martin Warren. 2009. Uncovering the extent of the phraseological tendency: Towards a systematic analysis of concgrams. Applied Linguistics 30(2). 236-252.

Cisneros, David J. 2008. Contaminated communities: The metaphor of "Immigrant as Pollutant" in media representations of immigration. Rhetoric and Public Affairs 11(4). 569-601.

Croft, William. 1993. The role of domains in the interpretation of metaphors and metonymies. Cognitive Linguistics 4(4). 335-370.

Dancygier, Barbara \& Eve Sweetser. 2014. Figurative language. Cambridge: Cambridge University Press.

David, Oana. 2016. Metaphor in the grammar of argument realization. Berkeley, CA: University of California, Berkeley dissertation.

David, Oana, Ellen Dodge, Jissup Hong, Elise Stickles \& Eve Sweetser. 2014. Building the MetaNet metaphor repository: The symbiosis of metaphor analysis and construction grammar. Paper presented at the 8th International Conference on Construction Grammar (ICCG 8), Osnabrück, Germany.

David, Oana, George Lakoff \& Elise Stickles. 2016. Cascades in metaphor and grammar: A case study of metaphors in the gun debate. Constructions and Frames 8(2). 214-255.

Davies, Mark. 2008-present. The corpus of contemporary American English: 450 million words, 1990-present [Online Corpus].

Deignan, Alice. 2005. Metaphor and corpus linguistics. Amsterdam: John Benjamins.

Deignan, Alice. 2012. Figurative language in discourse. In Hans-Jörg Schmid (ed.), Cognitive pragmatics, 437-462. Berlin: Mouton de Gruyter.

Demmen, Jane, Elena Semino, Zsófia Demjén, Veronika Koller, Andrew Hardie, Paul Rayson \& Sheila Payne. 2015. A computer-assisted study of the use of violence metaphors for cancer and end of life by patients, family carers and health professionals. International Journal of Corpus Linguistics 20(20). 205-231.

Dodge, Ellen, Jissup Hong \& Elise Stickles. 2015. Deep semantic automatic metaphor analysis. Paper presented at The Third Workshop on Metaphor in NLP, Denver, Colorado.

Dunn, Jonathan. 2011. Gradient semantic intuitions of metaphoric expressions. Metaphor and Symbol 26(1). 53-67.

Dunn, Jonathan. 2015. Three types of metaphoric utterances that can synthesize theories of metaphor. Metaphor and Symbol 30(1). 1-23.

Eeg-Olofsson, Mats \& Bengt Altenberg. 1996. Recurrent word patterns in the London-Lund Corpus: Coverage and use for word-class tagging. Language and Computers 16. 97-108. 
El Refaie, Elizabeth. 2001. Metaphors we discriminate by: Naturalized themes in Austrian newspaper articles about asylum seekers. Journal of Sociolinguistics 5(3). 352-372.

Feldman, Jerome \& Srini Narayanan. 2004. Embodied meaning in a neural theory of language. Brain and Language 89. 385-392.

Fillmore, Charles. 1982. Frame semantics. In The Linguistic Society of Korea (eds.), Linguistics in the morning Calm: Selected papers from SICOL-1981, 111-137. Seoul: Hanshin.

Fillmore, Charles. 1985. Frames and the semantics of understanding. Quaderni di Semantica 6. 222-254.

Fillmore, Charles \& Collin Baker. 2010. A frames approach to semantic analysis. In Bernd Heine \& Heiko Narrog (eds.), The Oxford handbook of linguistic analysis, 313-339. Oxford: Oxford University Press.

Gallese, Vittorio \& George Lakoff. 2005. The brain's concepts: The role of the sensorimotor system in reason and language. Cognitive Neuropsychology 22. 455-479.

Gibbs, Raymond W. 1984. Literal meaning and psychological theory. Cognitive Science 8. 275304.

Gibbs, Raymond W. 2017. The metaphor wars. Cambridge: Cambridge University Press.

Gibbs, Raymond W. \& Nandini P. Nayak. 1989. Psycholinguistic studies on the syntactic behavior of idioms. Cognitive Psychology 21. 100-138.

Goldberg, Adele. 1995. Constructions: A construction Grammar approach to argument structure. Chicago: University of Chicago Press.

Grady, Joseph. 1997. Foundations of meaning: Primary metaphors and primary scenes. Berkeley, CA: University of California, Berkeley dissertation.

Grady, Joseph. 1999. A typology of motivation for conceptual metaphor: Correlation vs. resemblance. In Raymond W. Gibbs \& Gerard J. Steen (eds.), Metaphor in cognitive linguistics, 79-100. Amsterdam: Benjamins.

Grady, Joseph. 2005. Primary metaphors as inputs to conceptual integration. Journal of Pragmatics 37. 1595-1614.

Gunkel, Lutz \& Gisela Zifonun. 2008. Constraints on relational-adjective noun constructions: A comparative view on English, German and French. Zeitschrift für Anglistik und Amerikanistik 56(3). 283-302.

Halliday, Michael A. K. 1967. Notes on transitivity and theme in English (Part 2). Journal of Linguistics 3(2). 199-244.

Hausmann, Franz J. 2007. Apprendre le vocabulaire, c'est apprendre les collocations. In E. Haag (ed.), Franz Josef Hausmann: Collocations, Phraséologie, lexicographie. Études 1997-2007, 49-61. Aachen: Shaker.

Herbst, Thomas, Susen Faulhaber \& Peter Uhrig (eds.). 2011. The phraseological view of language: A tribute to John Sinclair. Berlin: De Gruyter Mouton.

Huddleston, Rodney D. \& Geoffrey K. Pullum. 2002. The Cambridge grammar of the English language. Cambridge and New York: Cambridge University Press.

Hunston, Susan. 2002. Corpora in applied linguistics. Cambridge: Cambridge University Press.

Jäkel, Olaf. 1993. Is metaphor really a one-way street? One of the basic tenets of the cognitive theory of metaphor put to the test. In C.L.E.A.R. Series. Department of English, Hamburg University and the Department of American Studies, ELTE, Budapest.

Kilgarriff, Adam, Vít Baisa, Jan Bušta, Miloš Jakubíček, Vojtěch Kovvář, Jan Michelfeit, Pavel Rychlý \& Vít Suchomel. 2014. The Sketch Engine: Ten years on. Lexicography 1. 7-36.

Koller, Veronika, Andrew Hardie, Paul Rayson \& Elena Semino. 2008. Using a semantic annotation tool for the analysis of metaphor in discourse. Metaphorik.de 15. 141-160. 
Kövecses, Zoltán. 2002. Metaphor, 1st edn. Oxford: Oxford University Press.

Kövecses, Zoltán. 2010. Metaphor, 2nd edn. Oxford: Oxford University Press.

Kövecses, Zoltán. 2015. Where metaphors come from: Reconsidering context in metaphor. Oxford: Oxford University Press.

Lakoff, George. 1987. Women, fire, and dangerous things: What categories reveal about the mind. Chicago: University of Chicago Press.

Lakoff, George. 1990a. The syntax of metaphoric semantic roles. In James Pustejovsky (ed.), Studies in linguistics and philosophy. Dordrecht: Kluwer Academic Publishers.

Lakoff, George. 1990b. The invariance hypothesis: Is abstract reason based on image schemas? Cognitive Linguistics 1. 39-74.

Lakoff, George. 1993. The contemporary theory of metaphor. In Andrew Ortony (ed.), Metaphor and thought, 2nd edn., 202-251. Cambridge: Cambridge University Press.

Lakoff, George. 1997. Moral politics: What conservatives know that Liberals don't. Chicago: University of Chicago Press.

Lakoff, George. 2008. The neural theory of metaphor. In Raymond W. Gibbs (ed.), Cambridge handbook of metaphor and thought, 17-38. New York: Cambridge University Press.

Lakoff, George \& Mark Johnson. 1980. Metaphors we live by. Chicago: University of Chicago Press.

Lakoff, George \& Mark Johnson. 1999. Philosophy in the flesh: The embodied mind and its challenge to western thought. New York: Basic Books.

Langacker, Ronald. 1987. Foundations of cognitive grammar 1. Stanford: Stanford University Press.

Langacker, Ronald. 1991. Foundations of cognitive grammar 2. Stanford: Stanford University Press. Langacker, Ronald. 1999. Grammar and conceptualization. Berlin: Mouton de Gruyter.

Langacker, Ronald. 2009. Investigations in cognitive grammar. Berlin: Mouton de Gruyter.

Lederer, Jenny. 2016. Finding source domain triggers: How corpus methodologies aid in the analysis of conceptual metaphor. International Journal of Corpus Linguistics 21(4). 527558.

L'Hôte, Emily. 2014. Identity, narrative and metaphor: A corpus-based cognitive analysis of new labour discourse. London: Palgrave Macmillan.

McCloskey, Deirdre. N. 1986. The rhetoric of economics. Brighton, UK: Wheatsheaf Books and Harvester Press.

McEnery, Tony \& Andrew Wilson. 2001. Corpus linguistics: An introduction. Edinburgh: Edinburgh University Press.

Mikkelsen, Line. 2005. Copular clauses: Specification, predication and equation. Amsterdam: John Benjamins.

Moder, Carol Lynn. 2010. Two puzzle pieces: Fitting discourse context and constructions into cognitive metaphor theory. English Text Construction 3. 294-320.

Moore, Kevin. 2006. Space-to-time mappings and temporal concepts. Cognitive Linguistics 17. 199-244.

Moore, Kevin. 2014. The spatial language of time metaphor, metonymy, and frames of reference. Amsterdam: John Benjamins.

Musolff, Andreas. 2006. Metaphor scenarios in public discourse. Metaphor and Symbol 21(1). 23-38.

Núñez, Rafael \& Eve Sweetser. 2006. With the future behind them: Convergent evidence from Aymara language and gesture in the crosslinguistic comparison of spatial construals of time. Cognitive Science 30. 401-450. 
O'Brien, Gerald. 2003. Indigestible food, conquering hordes, and waste materials: Metaphors of immigrants and the early immigration restriction debate in the United States. Metaphor and Symbol 18(1). 33-47.

Ooi, Vincent B. Y. 2008. Lexis of electronic gaming on the web: A Sinclairian approach. International Journal of Lexicography 21(3). 311-323.

Oster, Ulrike. 2010. Using corpus methodology for semantic and pragmatic analyses: What can corpora tell us about the linguistic expression of emotions? Cognitive Linguistics 21(4). 727-763.

Petruck, Miriam R. L. 2016. Introduction to MetaNet. Constructions and Frames 8(2). 133-140. Pinker, Steven. 2006. Block that metaphor! The New Republic.

Pinker, Steven. 2007. The stuff of thought: Language as a window into human nature. New York: Viking.

Pragglejaz Group. 2007. MIP: A method for identifying metaphorically used words in discourse. Metaphor and Symbol 22(1). 1-39.

Reddy, Michael J. 1979. The conduit metaphor - A case of frame conflict in our language about language. In A. Ortony (ed.), Metaphor and thought, 284-297. Cambridge: Cambridge University Press.

Ruiz de Mendoza, F. J. 2017. Metaphor and other cognitive operations in interaction: From basicity to complexity. In B. Hampe (ed.), Metaphor: embodied cognition, and discourse, 138-159. Cambridge: Cambridge University Press.

Ryder, Mary Ellen. 1994. Ordered chaos: The interpretation of English noun-noun compounds. Berkeley: University of California Press.

Santa Ana, Otto. 1999. 'Like an animal I was treated': Anti-immigrant metaphor in US public discourse. Discourse and Society 10(2). 191-224.

Santa Ana, Otto. 2002. Brown tide rising: Metaphors of Latinos in contemporary American public discourse. Austin: University of Texas Press.

Scott, Michael \& Christopher Tribble. 2006. Textual patterns: Keywords and corpus analysis in language education. Amsterdam: John Benjamins.

Shenker-Osorio, Anat. 2012. Don't buy it: The trouble with talking nonsense about the economy. Philadelphia: PublicAffairs.

Shutova, Ekaterina. 2015. Design and evaluation of metaphor processing systems. Computational Linguistics 41(4). 579-623.

Shutova, Ekaterina \& Simone Teufel. 2010. Metaphor corpus annotated for source-target domain mappings. Proceedings of LREC 2010. Valetta, Malta.

Sinclair, John McH. 1991. Corpus, concordance, collocation. Oxford: Oxford University Press.

Sinclair, John. McH. 1994. Trust the text: Language, corpus, and discourse. London: Routledge.

Sinclair, J. McH. 1996. The search for units of meaning. Textus 9(1). 75-106.

Sinclair, John. McH. 1998. The lexical item. In E. Weigland (ed.), Contrastive Lexical semantics, 1-24. Amsterdam: John Benjamins.

Sinclair, J. McH. 2004. Introduction. In J. M. Sinclair (ed), How to use corpora in language teaching, 1-13. Amsterdam: John Benjamins.

Skinnemoen, Jorunn. 2009. Metaphors in climate change discourse. Oslo: University of Oslo dissertation.

Skorczynska, Hanna \& Alice Deignan. 2006. Readership and purpose in the choice of economics metaphors. Metaphor and Symbol 21(2). 87-104.

Steen, Gerard J. 2007. Finding metaphor in grammar and usage: A methodological analysis of theory and research. Amsterdam: John Benjamins. 
Steen, Gerard J. 2011. Metaphor, language, and discourse processes. Discourse Process 48(8). 585-591.

Steen, Gerard, J. 2015. Developing, testing, and interpreting deliberate metaphor theory. Journal of Pragmatics 90. 67-72.

Steen, Gerard J., Aletta G. Dorst, J. Berenike Herrmann, Anna Kaal, Tina Krennmayr \& Trijnytje Pasma. 2010. A method for linguistic metaphor identification. From MIP to MIPVU. Amsterdam: Benjamins.

Stefanowitsch, Anatol. 2005. The function of metaphor: Developing a corpus-based perspective. International Journal of Corpus Linguistics 10(2). 161-198.

Stefanowitsch, Anatol. 2006. Corpus-based approaches to metaphor and metonymy. In Anatol Stefanowitsch \& Stefan T. Gries (eds.), Corpus-based approaches to metaphor and metonymy, 1-16. Berlin, Germany: Mouton de Gruyter.

Stickles, Elise, Oana David, Ellen Dodge \& Jisup Hong. 2016. Formalizing contemporary conceptual metaphor theory: A structured repository for metaphor analysis. Constructions and Frames 8(2). 166-213.

Stubbs, M. 2002. Words and phrases: Corpus studies of lexical semantics. Oxford: Blackwell.

Sullivan, Karen. 2007. Grammar in metaphor: A construction grammar account of metaphoric language. Berkeley, CA: University of California, Berkeley dissertation.

Sullivan, Karen. 2009. Grammatical constructions in metaphoric language. In B. LewandowskaTomaszczyk \& K. Dziwirek (eds.), Studies in cognitive corpus linguistics. Frankfurt: Peter Lang Publishers.

Sullivan, Karen. 2013. Frames and constructions in metaphoric language. Amsterdam: John Benjamins Publishing.

Sullivan, Karen. 2016. Integrating constructional semantics and conceptual metaphor. Constructions and Frames 8(2). 141-165.

Talmy, Leonard. 1978. Figure and ground in complex sentences. In Joseph Greenberg (ed.), Universals of Human Language 4: Syntax, 625-649. Stanford, CA: Stanford University Press.

Talmy, Leonard. 2000a. Toward a cognitive semantics: Volume 1, concept structuring systems. Cambridge: MIT Press.

Talmy, Leonard. 2000b. Toward a cognitive semantics: Volume 2, typology and process in concept structuring. Cambridge: MIT Press.

Thibodeau, Paul \& Lera Boroditsky. 2011. Metaphors we think with: The role of metaphor in reasoning. PLOS One 6(2). e16782.

Thibodeau, Paul. \& Lera Boroditsky. 2013. Natural language metaphors covertly influence reasoning. PLOS One 8(1). e52961.

Traugott, Elizabeth. 1985. 'Conventional' and 'dead' metaphors revisited. In Wolf Paprotte \& René Dirven (eds.), The ubiquity of metaphor, 17-56. Amsterdam: Benjamins.

Volmert, Andrew, Michael Baran, Nathaniel Kendall-Taylor, Eric Lindland, Abigail Haydon, Shannon Arvizu \& Alexis Bunten. 2013. "Just the Earth doing its own thing": Mapping the gaps between expert and public understandings of oceans and climate change.

Washington, DC: FrameWorks Institute. http://www.frameworksinstitute.org/assets/files/ cC_oceans_mtg.pdf

Winter, Bodo. 2016. The sensory structure of the English lexicon. Merced, CA: University of California, Merced dissertation. 